\title{
Biodiesel dari Minyak Goreng Sawit Bekas dengan Katalis Heterogen CaO: Studi Penentuan Rasio Mol Minyak/Metanol dan Waktu Reaksi Optimum
}

\author{
Haryono*, Iman Rahayu, Yati B. Yulyati \\ Departemen Kimia, Fakultas Matematika dan Ilmu Pengetahuan Alam, Universitas Padjadjaran \\ Jl. Raya Bandung-Sumedang KM. 21 Jatinangor-Sumedang 45363
}

\section{Artikel histori :}

Diterima 16 Desember 2015 Diterima dalam revisi 24 April 2016 Diterima 24 April 2016 Online 01 Juni 2016

\begin{abstract}
ABSTRAK: Keterbatasan daya dukung bahan bakar fosil terhadap pemenuhan kebutuhan energi yang berkelanjutan dan ramah lingkungan, telah mengarahkan masyarakat pada upayaupaya untuk menemukan dan mengembangkan sumber-sumber energi alternatif yang bersifat baru dan terbarukan. Salah satunya jenis energi terbarukan tersebut adalah biodiesel. Penelitian ini bertujuan untuk mensintesis biodiesel dengan memanfaatkan limbah minyak goreng sawit bekas. Penelitian dikhususkan pada penentuan rasio mol minyak/metanol dan waktu reaksi transesterifikasi dengan katalis basa heterogen $\mathrm{CaO}$. Rasio mol minyak/metanol dipelajari pada variasi $1 / 5,1 / 10,1 / 15$, dan 1/20. Sedangkan waktu reaksi divariasikan selama 1, 1,5, 2, 2,5, dan 3 jam. Reaksi dilakukan pada suhu $65^{\circ} \mathrm{C}$ dan kadar katalis $\mathrm{CaO}$ sebanyak 3\%. Hasil penelitian menunjukkan bahwa kondisi optimum reaksi dicapai pada saat sintesis biodiesel dilakukan pada rasio mol minyak/metanol sebesar 1/15 dengan lama reaksi 2,5 jam. Pada kondisi reaksi tersebut diperoleh biodiesel dengan beberapa parameter kualitas yang diuji telah sesuai dengan SNI untuk Biodiesel (SNI-04-7182-2006), yaitu: densitas $0,867 \mathrm{~g} / \mathrm{cm}^{3}$, viskositas $5,28 \mathrm{~mm}^{2} / \mathrm{s}$ (pada suhu $40^{\circ} \mathrm{C}$ ), titik kilat $182^{\circ} \mathrm{C}$, angka asam $0,28 \mathrm{mg} \mathrm{KOH} / \mathrm{g}$, gliserol bebas $0,014 \%$, gliserol total $0,10 \%$, kadar ester $97,8 \%$, dan angka iod $31,62 \%$, serta yield biodiesel sebesar $86,0 \%$.
\end{abstract}

Kata Kunci: biodiesel; katalis $\mathrm{CaO}$; minyak goreng bekas; rasio mol; waktu reaksi.

\section{Pendahuluan}

Efek rumah kaca dan perubahan iklim global merupakan isu kontroversial dan kritis yang berdampak terhadap industri energi, pembuat kebijakan publik, dan masyarakat. Oleh karena itu, sektor energi, transportasi, dan industri sudah seharusnya memanfaatkan bahan bakar bersifat terbarukan, berkelanjutan, dan ramah lingkungan. Salah satu jenis bahan bakar tersebut adalah biodiesel (Chung, 2013).

Dalam skala nasional, Indonesia masih menghadapi permasalahan energi yang relatif komplek. Pemanfaatan bahan bakar minyak (BBM) sebagai jenis energi dominan yang dikonsumsi, lebih besarnya laju konsumsi BBM dibandingkan laju produksi, harga minyak bumi mentah yang fluktuatif, dan cadangan minyak bumi semakin berkurang merupakan permasalahan yang selalu melekat pada jenis energi fosil ini (BPPT, 2014). Sebagai upaya mengurangi ketergantungan terhadap BBM, pemerintah Indonesia telah membuat kebijakan sebagai bagian dari salah satu paket kebijakan ekonomi, salah satunya adalah penerbitan Peraturan Menteri ESDM No. 20 Tahun 2014 (perubahan kedua Peraturan Menteri ESDM No. 32 Tahun 2008) tentang penyediaan, pemanfaatan, dan tata niaga bahan bakar nabati sebagai bahan bakar lain.

Dalam aspek bahan baku, biodiesel dapat dibuat dari minyak nabati, lemak hewan, atau sumber-sumber lainnya seperti limbah minyak goreng. Namun asal-usul dan kualitas bahan baku tersebut akan berdampak pada perubahan proses produksi yang dibutuhkan (Gashaw \& Teshita, 2014).

Dalam hal ketersediaan, minyak goreng bekas, terutama jenis minyak sawit relatif melimpah dan mudah diperoleh. Hal tersebut dapat diperkirakan dari peningkatan laju pertumbuhan produksi kelapa sawit tahun 2004 - 2014 sekitar $11,09 \%$ per tahun (Direktorat Jenderal Perkebunan, 2014) dan proyeksi konsumsi CPO (crude palm oil) pada tahun 2015 untuk produksi minyak goreng dan margarin sekitar 5,9 juta ton atau 54,63\% dari total produksi CPO (GAPKI, 2015).

Pada reaksi pembentukan biodiesel umumnya dibutuhkan peranan katalis. Dengan pertimbangan minyak goreng bekas memiliki bilangan asam dan kadar air relatif tinggi, penggunaan katalis basa homogen akan menimbulkan berbagai masalah teknis, seperti: reaksi penyabunan, meningkatkan viskositas biodiesel, dan pemisahan katalis yang relatif sulit (Mat et al, 2012).

Salah satu alternatif untuk mengatasi masalah tersebut adalah penggunaan katalis padat berupa $\mathrm{CaO}$ (Juan et al, 2014, Viriya-empikul et al, 2012, Ranjan et al, 2012). Mekanisme reaksi sintesis biodiesel dengan katalis $\mathrm{CaO}$ telah dipelajari oleh beberapa peneliti, salah satunya oleh Lee et al (2009), seperti yang ditampilkan pada Gambar 1. Sedangkan terkait dengan mutu biodiesel, Indonesia melalui Badan Standardisasi Nasional telah merumuskan 
standar mutu biodiesel dalam bentuk SNI Biodiesel (SNI04-7182-2006).

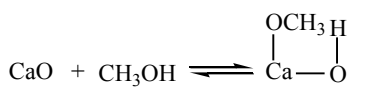<smiles>[R]C(=O)OCC(COC([R])=O)OC([R])=O</smiles><smiles>[R]C([R])(OC)OCC1COC([R])([R])OC([R])(OC)OC1</smiles><smiles>[R]C(=O)OC(COC([R])([R])[R])COC([R])([R])OC</smiles><smiles>[R]C(=O)OCC(CO)OC([R])=O</smiles><smiles>[R]C(=O)OC[C@H](CO)OC([R])=O</smiles><smiles>C=CO[GeH3]</smiles><smiles>[R]C(=O)OCC(CO)OC([R])=O</smiles>

Gambar 1. Mekanisme reaksi pembentukan 1 mol metil ester (biodiesel) berkatalis $\mathrm{CaO}$

Penelitian ini bertujuan untuk menentukan kondisi reaksi optimum berupa rasio mol minyak terhadap metanol dan waktu reaksi pada sintesis biodiesel dari minyak goreng sawit bekas dengan katalis $\mathrm{CaO}$.

Kondisi optimum didasarkan pada perbandingan kesesuaian antara biodiesel yang dihasilkan dengan SNI Biodiesel. Parameter mutu yang diperbandingkan meliputi: densitas, viskositas, angka asam, kadar gliserol bebas dan total, angka iod, dan kadar ester.

\section{Metode Penelitian}

\subsection{Bahan penelitian}

Bahan-bahan yang digunakan dalam penelitian ini antara lain: minyak goreng sawit bekas, metanol teknis, $\mathrm{CaO}$, kalium hidroksida, natrium hidroksida, kalium iodin, kalium iodat, etanol $95 \%$, air distilasi, dan natrium tiosulfat.

\subsection{Alat penelitian}

Alat-alat yang digunakan pada penelitian ini antara lain adalah: reaktor biodiesel berupa labu gelas leher tiga, hot plate magnetic stirrer, seperangkat alat distilasi, viskometer, seperangkat alat analisis dengan titrasi, seperangkat alat GC-MS Shimadzu QP-5000, oven, instrumen adsorpsi BET Quantachrome Instruments, dan instrumen XRD Philips Analytical.

\subsection{Prosedur penelitian}

Penelitian ini dilakukan melalui 6 tahap kegiatan, yaitu: karakterisasi katalis dengan metode XRD dan adsorpsi isoterm BET (Brunauer, Emmet, and Teller) gas $\mathrm{N}_{2}$, pemurnian minyak goreng sawit bekas, analisis sifat fisik dan kimia terhadap minyak goreng bekas, sintesis biodiesel dengan katalis $\mathrm{CaO}$, pemurnian biodiesel, dan analisis mutu biodiesel.

Penelitian ini ditekankan pada penentuan rasio mol minyak terhadap metanol dan waktu reaksi (Juan et al, 2014, Viriya-empikul et al, 2012, Ranjan et al, 2012). Rasio mol minyak terhadap metanol dipelajari pada variasi $1 / 5,1 / 10,1 / 15$, dan $1 / 20$, sedangkan waktu reaksi divariasikan selama 1, 1,5, 2, 2,5, dan 3 jam. Reaksi sintesis biodiesel dilaksanakan pada suhu $65^{\circ} \mathrm{C}$ dan kadar katalis $\mathrm{CaO}$ sebesar 3\%-b.

Untuk mengetahui perubahan jenis dan komposisi asam lemak pada minyak goreng bekas dibandingkan dengan di dalam biodiesel, dilakukan analisis dengan GC-MS (Gas Chromatography-Mass Spectroscopy). Pada penelitian ini parameter mutu biodiesel yang diuji adalah densitas, viskositas, angka asam, kadar gliserol bebas dan total, angka iod, dan kadar ester.

\section{Hasil dan Pembahasan}

\subsection{Karakteristik Katalis $\mathrm{CaO}$}

Katalis $\mathrm{CaO}$ yang digunakan pada penelitian ini sebelum digunakan, dikarakterisasi untuk mengetahui keberadaan dan tingkat kristalinitasnya, serta karakteristik permukaan dan porinya. Hasil karakterisasi ditampilkan pada Gambar 2 dan Tabel 1.

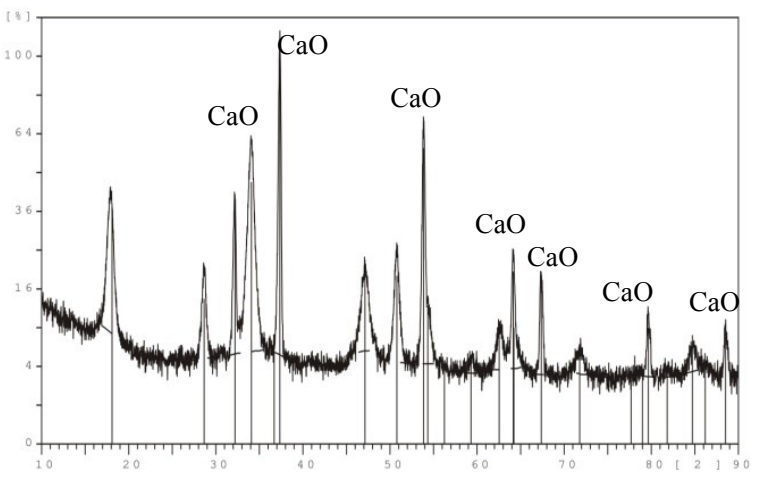

Gambar 2. Difraktogram XRD dari katalis $\mathrm{CaO}$

Tabel 1. Karakteristik permukaan dan pori katalis $\mathrm{CaO}$ dengan metode adsorpsi isoterm BET

\begin{tabular}{ll}
\hline Karakteristik & Nilai \\
\hline Luas permukaan spesifik $\left(\mathrm{m}^{2} / \mathrm{g}\right)$ & 2,17 \\
Volume pori rata-rata spesifik $\left(\mathrm{cm}^{3} / \mathrm{g}\right)$ & 0,02 \\
Diameter pori rata-rata $(\mathrm{nm})$ & 28,5 \\
\hline
\end{tabular}

Gambar 2 menunjukkan bahwa katalis yang digunakan pada penelitian ini tersusun dari $\mathrm{CaO}$ dengan struktur kristalin pada beberapa sudut difraksi $2 \theta$, walaupun masih dijumpai adanya pengotor. Karakteristik permukaan katalis ditampilan sebagai parameter luas permukaan spesifik, volume pori rata-rata spesifik, dan diameter rata-rata pori. 


\subsection{Hasil Analisis Minyak Goreng Sawit Bekas}

Minyak goreng sawit bekas setelah dimurnikan dari pengotor-pengotornya, dilakukan analisis beberapa parameter sifat fisika dan kimia sebagai rujukan pembandingan antara minyak sebelum dengan setelah terkonversi menjadi biodiesel dan sebagai penentuan rasio mol minyak terhadap metanol pada tahap sintesis biodiesel. Hasil analisis terhadap minyak goreng sawit bekas ditampilkan pada Tabel 2 dan Tabel 3.

Berdasarkan hasil penelitian yang ditampilkan pada Tabel 2, dapat disimpulkan bahwa minyak goreng sawit bekas yang digunakan sebagai bahan baku sintesis biodiesel memiliki kualitas relatif rendah. Hal tersebut nampak dari 3 parameter analisis. Pada sintesis biodiesel, jika digunakan katalis basa homogen, minyak bahan baku dipersyaratkan memiliki angka asam maksimal 1,0\%-b atau sekitar 2,0 mg KOH/g minyak (Gashaw \& Teshita, 2014).

Tabel 2. Hasil analisis minyak goreng sawit bekas

\begin{tabular}{ll}
\hline Parameter & Hasil \\
\hline Bilangan asam, $\mathrm{mg} \mathrm{KOH} / \mathrm{g}$ & 25,0 \\
Densitas $\left(40^{\circ} \mathrm{C}\right), \mathrm{g} / \mathrm{mL}$ & 0,911 \\
Viskositas kinematika $\left(40^{\circ} \mathrm{C}\right), \mathrm{cSt}$ & 60,8 \\
\hline
\end{tabular}

Tabel 3. Hasil analisis minyak goreng sawit bekas

\begin{tabular}{lll}
\hline Asam lemak & Shorthand & Kadar (\%) \\
\hline Asam oleat & C18:1 & 54,85 \\
Asam palmitat & C16:0 & 29,35 \\
Asam stearat & C18:0 & 4,90 \\
Asam miristat & C14:0 & 1,50 \\
Asam laurat & C12:0 & 1,29 \\
\hline
\end{tabular}

Jenis dan komposisi asam lemak yang terkandung dalam minyak goreng sawit bekas ditampilkan pada Tabel 3. Berdasarkan tabel tersebut, nampak bahwa minyak goreng sawit bekas didominasi oleh asam lemak jenis asam oleat dengan persen kelimpahan $54,85 \%$ dan asam palmitat $(29,35 \%)$.

\subsection{Hasil sintesis biodiesel}

Pada tahap sintesis biodiesel, berdasarkan jenis parameter kondisi reaksi yang dipelajari diperoleh hasil seperti yang ditampilkan pada Gambar 3, 4, dan 5. Sebagai parameter untuk menentukan keoptimalan kondisi reaksi, digunakan parameter berupa yield, densitas, dan viskositas dari biodiesel yang dihasilkan. Selain itu, penentuan kondisi optimal tersebut juga didasarkan pada pertimbangan efisiensi konsumsi energi untuk pengontakan antar reaktan dan katalis.

Gambar 3 menunjukkan kecenderungan umum pada setiap lama reaksi bahwa semakin besar rasio mol minyak terhadap metanol, yield biodiesel semakin meningkat. Namun terjadi penurunan yield ketika digunakan rasio mol $1: 20$. Hal tersebut disebabkan karena pengunaan metanol yang semakin banyak pada sintesis biodiesel, maka kebutuhan metanol minimum (stoikiometris) semakin tercapai bahkan terlampaui, sehingga probabilitas pembentukan biodiesel sebagai produk akan lebih besar.

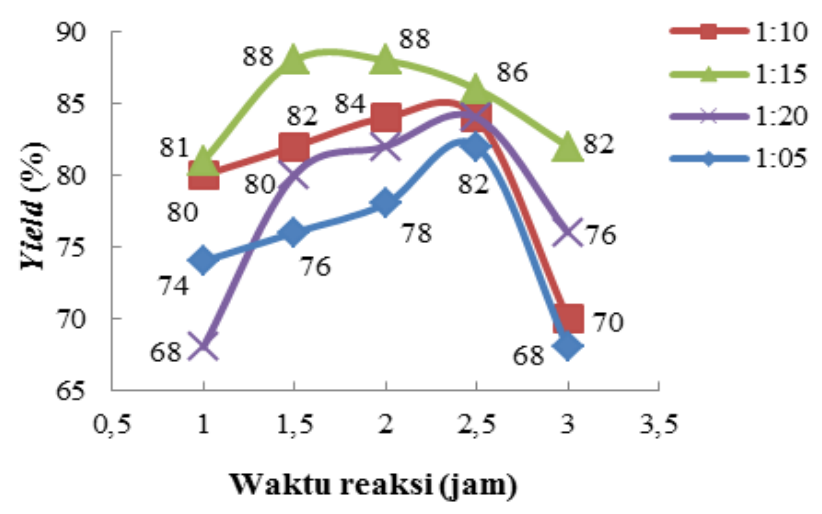

Gambar 3. Pengaruh lama reaksi terhadap yield biodiesel pada rasio mol minyak/me- tanol 1:5, 1:10, $1: 15,1: 20$

Selain itu, secara termodinamika, semakin banyaknya metanol akan mendorong reaksi ke arah pembentukan biodiesel (Thanh et al, 2012). Reaksi umum pembentukan biodiesel (metil ester) dari minyak (trigliserida) dan metanol adalah:

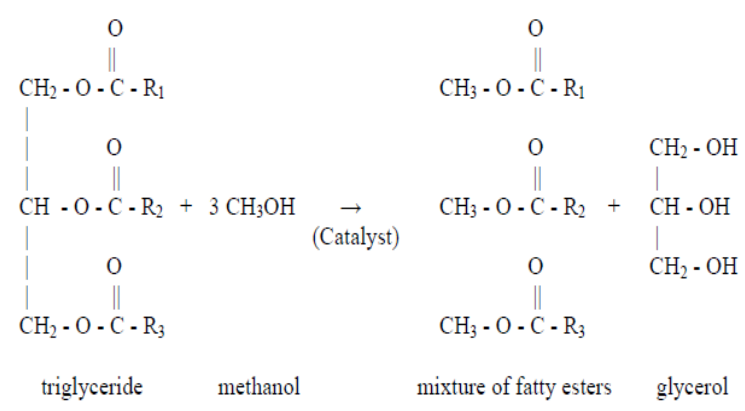

Namun demikian, pada penggunaan metanol yang melebihi kebutuhan optimum, diperlukan upaya lebih agar reaksi dapat berlangsung efektif, terutama terkait dengan efektivitas dan intensitas kontak antar reaktan dan katalis. Pada penelitian ini digunakan metode pengontakan antar reaktan dengan pengadukan berupa magnetic stirrer pada kecepatan putar tetap. Hal tersebut mengakibatkan pengontakan antar reaktan yang efektif tidak tercapai. Akibatnya yield biodiesel terjadi penurunan. Sedangkan jika ditinjau pada waktu reaksi yang semakin lama untuk setiap rasio mol tertentu, terjadi kecenderungan serupa. Penurunan yield biodiesel pada lama reaksi 3 jam kemungkinan disebabkan terjadinya penggerusan (pengecilan) ukuran dari $\mathrm{CaO}$ sebagai akibat gesekan antar permukaan partikel $\mathrm{CaO}$ maupun antara partikel $\mathrm{CaO}$ dengan pengaduk (magnetic bar). Pengecilan ukuran $\mathrm{CaO}$ ini menyebabkan semakin banyak biodiesel yang terjebak pada bagian mikropori $\mathrm{CaO}$ yang terbentuk, dan terikut di 
dalam $\mathrm{CaO}$ pada tahap pemisahan $\mathrm{CaO}$ dari biodiesel, sehingga mengurangi yield biodiesel.

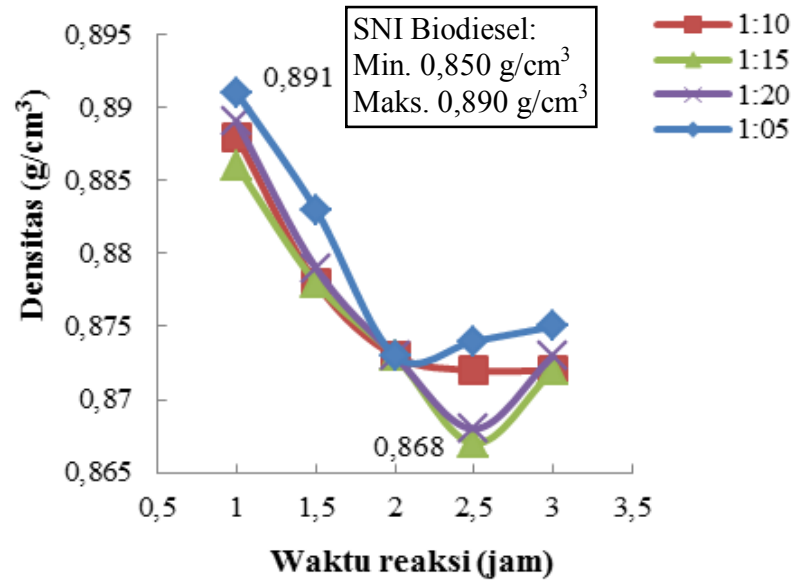

Gambar 4. Pengaruh lama reaksi terhadap densitas biodiesel pada rasio mol minyak/meta- nol 1:5, $1: 10,1: 15,1: 20$

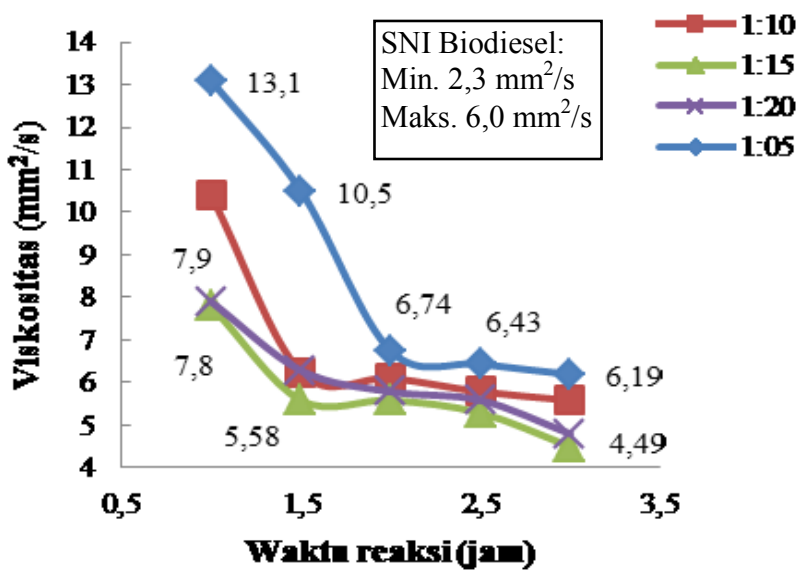

Gambar 5. Pengaruh lama reaksi terhadap viskositas biodiesel pada rasio mol minyak/metanol 1:5, $1: 10,1: 15,1: 20$

Pengaruh lama reaksi terhadap viskositas biodiesel pada berbagai rasio mol minyak/metanol ditampilkan pada Gambar 5. Secara umum menunjukkan kecenderungan bahwa semakin lama reaksi, viskositas biodiesel yang dihasilkan semakin turun. Hal tersebut mengindikasikan pengkonversian minyak goreng bekas menjadi biodiesel semakin meningkat. Pada reaksi selama 1 dan 1,5 jam, viskositas biodiesel yang dihasilkan masih relatif besar dan tidak memenuhi SNI Biodiesel. Sehingga dapat dikatakan, pada pelaksanaan reaksi dengan kedua waktu tersebut, pembentukan biodiesel relatif terbatas. Kecenderungan yang relatif sama pada pengkajian pengaruh lama reaksi terhadap densitas biodiesel pada berbagai rasio mol minyak/metanol seperti yang ditampilkan pada Gambar 4.

Pada penelitian ini, berdasarkan pertimbangan yield, densitas, viskositas biodiesel yang dihasilkan, dan efisiensi konsumsi metanol serta energi, dapat disimpulkan bahwa kondisi reaksi optimum dicapai pada penggunaan rasio mol minyak terhadap metanol sebesar 1:15 dan lama reaksi 2,5 jam.

Penampilan campuran hasil reaksi dan biodiesel yang telah dimurnikan pada penelitian ini disajikan pada Gambar 6.

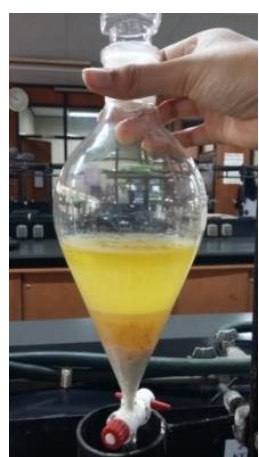

(a)

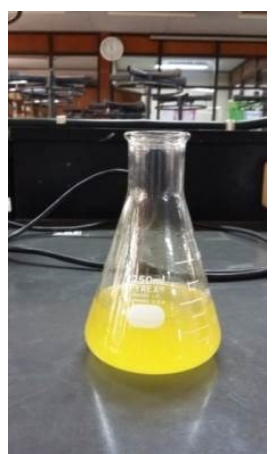

(b)
Gambar 6. (a) Campuran hasil reaksi: lapisan atas biodiesel, tengah gliserin, bawah katalis; (b) biodiesel yang telah dimurnikan

\subsection{Perbandingan mutu biodiesel}

Biodiesel yang diperoleh pada kondisi reaksi optimum selanjutnya dianalisis parameter mutu lainnya, meliputi: titik nyala, angka asam, kadar gliserol bebas, kadar gliserol total, kadar ester, dan angka iod, dan analisis jenis serta komposisi metil ester yang terdapat di dalam biodiesel dengan GC-MS. Hasil analisis parameter mutu dan perbandingannya dengan SNI Biodiesel ditampilkan pada Tabel 4, sedangkan hasil analisis biodiesel dengan GC-MS disajikan pada Tabel 5.

Tabel 4. Perbandingan Mutu antara Biodiesel menurut SNI dengan Hasil Penelitian

\begin{tabular}{|c|c|c|c|}
\hline \multirow{2}{*}{$\begin{array}{l}\text { Parameter } \\
\text { Mutu }\end{array}$} & \multirow[b]{2}{*}{ Satuan } & \multicolumn{2}{|l|}{ Nilai } \\
\hline & & $\begin{array}{l}\text { SNI } \\
\text { Biodiesel }\end{array}$ & Hasil \\
\hline Densitas $\left(40^{\circ} \mathrm{C}\right)$ & $\mathrm{g} / \mathrm{cm} 3$ & $\begin{array}{l}0,850- \\
0,890\end{array}$ & 0,867 \\
\hline $\begin{array}{l}\text { Viskositas } \\
(40 \mathrm{oC})\end{array}$ & $\mathrm{mm} 2 / \mathrm{s}$ & $2,3-6,0$ & 5,28 \\
\hline Titik nyala & $\mathrm{oC}$ & $\min .100$ & 182 \\
\hline Gliserol bebas & $\%$-massa & maks. 0,02 & 0,014 \\
\hline Gliserol total & $\%$-massa & maks. 0,24 & 0,10 \\
\hline Angka asam & $\begin{array}{l}\mathrm{mg} \\
\mathrm{KOH} / \mathrm{g}\end{array}$ & maks. 0,8 & 0,28 \\
\hline Kadar ester & $\%$-massa & $\min .96,5$ & 97,8 \\
\hline Angka iodium & $\mathrm{g} \mathrm{I} / 2 / 100 \mathrm{~g}$ & maks. 115 & 31,62 \\
\hline
\end{tabular}


Tabel 4 menunjukkan bahwa berdasarkan 8 parameter mutu biodisesl, biodiesel yang dihasilkan pada penelitian ini telah sesuai dengan SNI Biodiesel (SNI-04-7182-2006). Sedangkan jika dilakukan perbandingan berdasarkan parameter densitas, viskositas, dan angka asam antara minyak goreng sawit bekas dengan biodiesel hasil penelitian (data pada Tabel 2 dan Tabel 4), nampak bahwa telah terjadi penurunan yang signifikan pada ketiga parameter uji tersebut. Densitas turun dari $0,911 \mathrm{~g} / \mathrm{cm}^{3}$ menjadi $0,867 \mathrm{~g} / \mathrm{cm}^{3}$, viskositas turun dari $60,8 \mathrm{~mm} / \mathrm{s}$ menjadi $5,28 \mathrm{~mm}^{2} / \mathrm{s}$, dan angka asam turun dari $25,0 \mathrm{mg}$ $\mathrm{KOH} / \mathrm{g}$ menjadi $0,28 \mathrm{mg} \mathrm{KOH} / \mathrm{g}$. Penurunan densitas dan viskositas menunjukkan bahwa senyawa trigliserida pada minyak telah terkonversi menjadi biodiesel, sedangkan penurunan angka asam membuktikan bahwa asam lemak bebas di dalam minyak goreng bekas telah berhasil dikonversi menjadi metil esternya melalui reaksi esterifikasi.

Tabel 5. Jenis dan Komposisi Metil Ester dalam Biodiesel (hasil GC-MS)

\begin{tabular}{ll}
\hline Jenis Metil Ester & Kadar (\%) \\
\hline Metil oleat & 41,43 \\
Metil palmitat & 30,03 \\
Metil stearat & 8,21 \\
Metil miristat & 3,88 \\
Metil laurat & 2,54 \\
Metil Arakidat & 1,12 \\
\hline
\end{tabular}

\section{Kesimpulan}

1. Minyak goreng sawit bekas dapat dikonversi menjadi biodiesel dengan bantuan katalis $\mathrm{CaO}$

2. Kondisi reaksi optimum pada sintesis biodiesel dari minyak goreng sawit bekas dengan katalis $\mathrm{CaO}$ sebanyak $3 \%$ dan suhu reaksi $65^{\circ} \mathrm{C}$ dicapai ketika reaksi diselenggarakan pada rasio mol minyak terhadap metanol sebesar 1:15 dan selama 2,5 jam.

3. Pada kondisi reaksi optimum tersebut dihasilkan biodiesel yang telah sesuai dengan SNI Biodiesel berdasarkan 8 parameter mutu, yaitu: densitas, viskositas, titik kilat, angka asam, kadar gliserol bebas, kadar gliserol total, kadar ester, dan angka iodium.

4. Yield biodiesel yang dicapai pada kondisi reaksi optimum adalah sebesar $86 \%$.

5. Berdasarkan hasil analisis dengan GC-MS, jenis metil ester yang terdapat pada biodiesel pada penelitian secara dominan berupa metil oleat dan metil palmitat, sesuai dengan jenis asam lemak yang terdapat pada minyak goreng sawit bekas sebagai bahan baku.

\section{Daftar Pustaka}

Chung, J.N., 2013, Grand challenges in bioenergy and Biofuel Research: Engineering and Technology Development, Environmental, Impact, and
Sustainability, Energy Research-Frontiershin, University of Florida, USA.

BPPT (Badan Pengkajian dan Penerapan Teknologi), 2014, Outlook Energi Indonesia 2014: Pengembangan Energi untuk Mendukung Program Subsidi BBM.

Direktorat Jenderal Perkebunan, 2014, Pertumbuhan Kelapa Sawit, diakses dari www.ditjenbun.go.id (publikasi tanggal 21 November 2014).

GAPKI (Gabungan Pengusaha Kelapa Sawit Indonesia), 2015, Konsumsi Sawit di Indonesia, diakses dari www.sawitindonesia.com, publikasi tanggal 29 April 2015.

Gashaw A., Teshita, A., 2014, Production of biodiesel from waste cooking oil and factors affecting its formation: A review, International Journal of Renewable and Sustainable Energy, Vol. 3(5), pp. 92-98.

Juan, J.C, Hwei Voon Lee, H. V., Fitriyah, N., Nizah, R., Taufiq-Yap, Y. H., 2014, Heterogeneous base catalysts for edible palm and non-edible Jatropha-based biodiesel production, Chemistry Central Journal, Vol. 8 (10), pp. 1-9.

Lee, D.W., Park, Y.M., Lee, K.Y., 2009, Heterogeneous Base Catalysts for Transesterification in Biodiesel Synthesis, Catal Surv Asia, Vol. 13, pp. 63-77.

Mat, R., Samsudin, R.A., Mohamed, M., Johari, A., 2012, Solid Catalysts and Their Application in Biodiesel Production, Bulletin of Chemical Reaction Engineering \& Catalysis, Vol. 7 (2), pp. 142-149.

Ranjan, M.S., Kumar, M.M., Kumar, P.A., 2012, Preparation of Biodiesel from Crude oil of Simarouba glauca using $\mathrm{CaO}$ as a Solid Base Catalyst, Research Journal of Recent Sciences, Vol. 1, No. 9, pp. 49-53.

Thanh, L.T., Okitsu, K., Boi, L.V., Maeda, Y., 2012, Catalytic Technologies for Biodiesel Fuel Production and Utilization of Glycerol, Catalyst, Vol. 2, pp. 191222

Viriya-empikul, N., Krasae, P., Nualpaeng, W., Yoosuk, B., Faungnawakij, K., 2012, Biodiesel Production Over Ca-Based Solid Catalysts Derived from Industrial Wastes, Fuel, Vol 92, pp. 239-244. 